||||i||||||||||||||||

\title{
ファジイ入出力デー夕による可能性 $\mathrm{DEA}^{\dagger}$ 乾口 雅弘* 谷野 哲三*
}

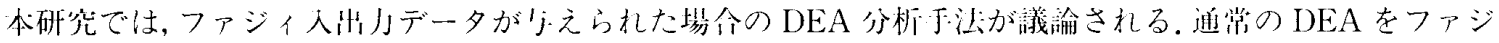

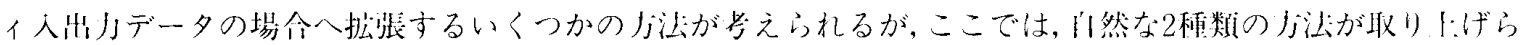

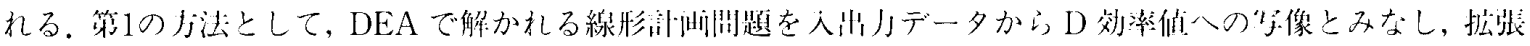

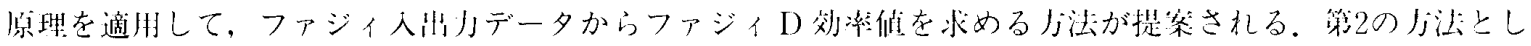

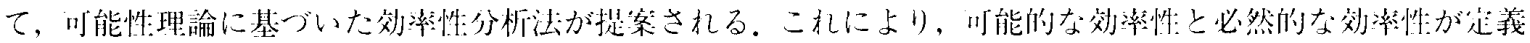

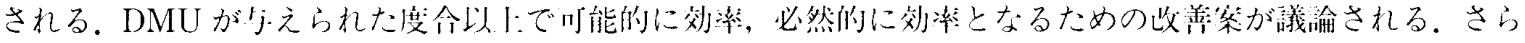

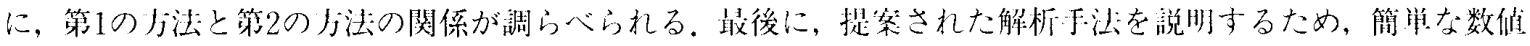
例がリえられる。
\end{abstract}

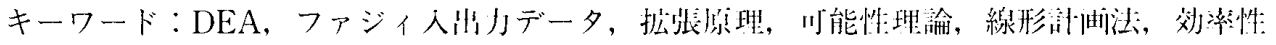

\section{1.はじめに}

本研究は, DEA (Data Envelopment Analysis; 岀絡 分析法) [1][2]へのファジイ理論の蒠入を狱みな文献 [3][4]に動機付けられな。これらは，いずれもりえら

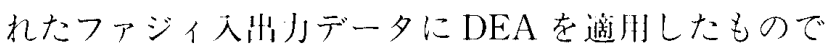

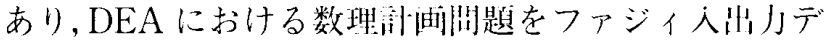

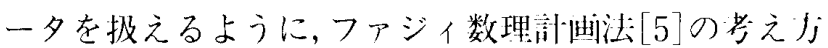
を導人した先駆的な砶究である。

これらのアプローチでは, D 效摔值[1][2]を求める

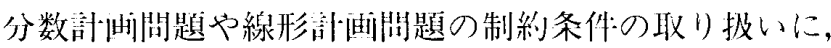
疑問が牛じる。たとえば，人ノの加車利が1となる制約 条件を考えると，ファジイ入力データの加重利は常に ファジィ数となるのでこれを算数1とすることができ ない，その絬果，得られた解(結果) を代人すると, D 效 摔佔のファジイ数に1を越える部分が你在する。 DMU (Decision Making Unit：意想沈定者)の效率佔が1以 トという条件を，最人值を1となるようにD效摔傾を

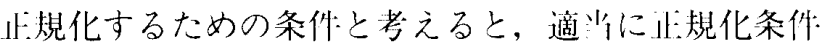
を変这しただけと捕らえられることもできるが, 1 にど の程度近いかにより效涞性の度合を求好ていた通常の

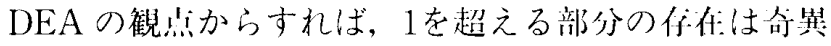
に感じられる。

また，文献 [3][4]では，効摔性に関する定義はなく，

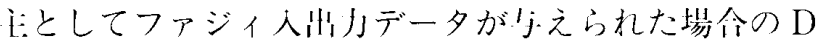
效摔㑤の起義と算出について議論されている。もちろ ん,これらのアプローチに执いて提案されたD 效摔佔。 等を解いて，效摔性を定義することも叮能ではあるが，

+ Possibilistic DEA with Fuzzy Input-Output Data Masahiro INUIGUCHI and Tetsuzo TANINO

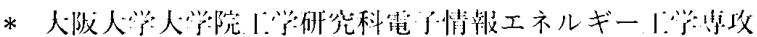
Graduate School of Engineering, Osaka University
その效率性の意味を理解することは少しやっかいなも のとなろう。

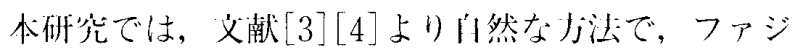

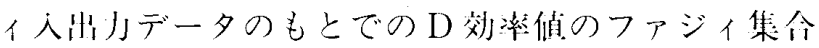
在求めるとともに, DEAに扔ける效泘性を叮能性理論

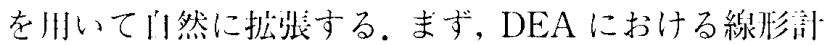

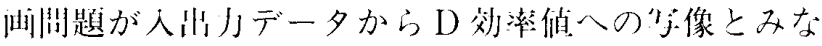

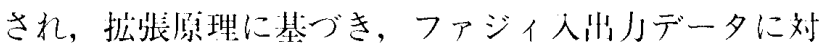

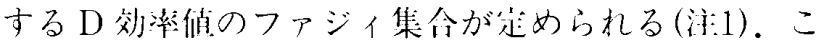
㓜により，1を超える部分が份住しないD效摔储のフ アジィ集命が求められる。次に, DMUが效摔的である ことを一一の事象と考え，それをDMUが效㳯的とな るファジィ人州打データの集命により定䈻する。この

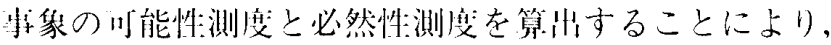
效摔的である叮能性:の度合と必然性の度合が是めら机 る。作意のDMUが方えら扎た度介以1:の叮能性で効

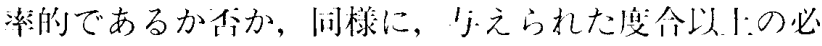

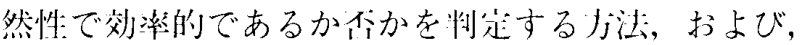

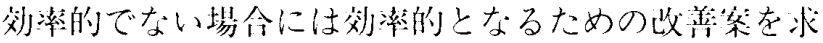
めるう法が議論される。さらに，述の二つのアプロ

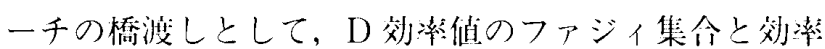
们である叮能性，必然性の成合との関係が論じられる。

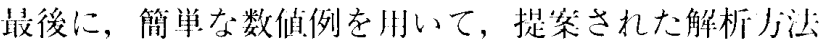
が说明される。

\section{2. 包絡分析法：DEA}

事紧体の経営効摔は，投人した資源から，どれだけ

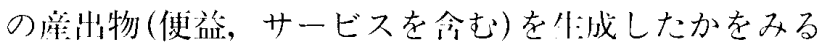
ことにより，㫦㑛することができる。たとえば，比の

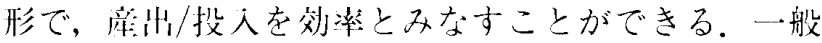
に，投人する资源には，资金，人手，物资など租々の

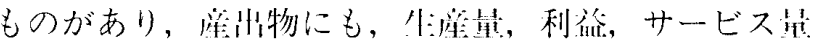


など，複数のものが仿在する。このように，束業体は， 多人力多出力システムとみることができる。

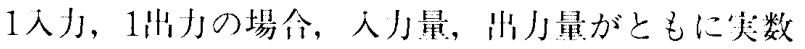

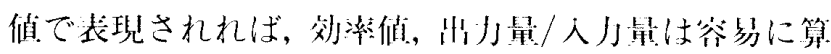
惊することができる。しかし，多人お，罗忺打の埸令，

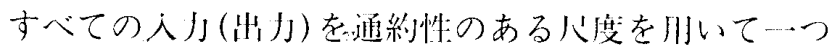

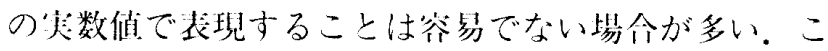

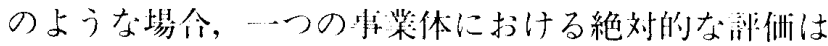
困難となる。仙絡分析法(DEA)では，间唡の人ノと忡 」をもつ他の複数の抖業体との相刘比較により，扑業

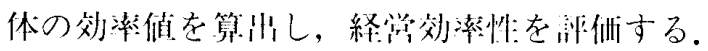

分析の刘象とする枯業体をDMU (Decision Mak

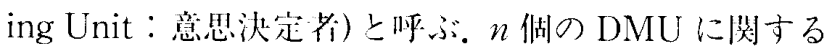
$m$ 倜の人Jデー夕を $m \times n$ 行列 $X=\left(x_{i k}\right), s$ 湖の虫 נデー夕を $s \times n$ 行列 $Y=\left(y_{j k}\right)$ 上寸る。このとき，K

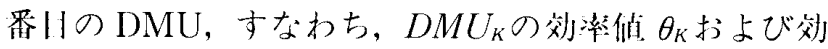

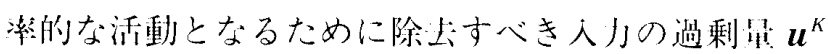

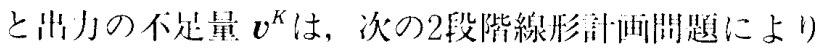
求められる

$$
\begin{aligned}
& \text { lex-min }\left(\theta_{K},-\sum_{i}^{m} u_{i}^{K}-\sum_{j}^{n} v_{j}^{K}\right) \\
& \text { subject to } \theta_{K} x_{i K}=\sum_{k}^{n} \lambda_{k} x_{i k}+u_{i}^{K}, \\
& y_{j K}=\sum_{k}^{n} \lambda_{k} y_{j k}-v_{j}^{K}, \\
& \theta_{K} \geq 0, \lambda_{k} \geq 0, u_{i}^{K} \geq 0, v_{j}^{K} \geq 0, \\
& i=1,2, \ldots, m, j=1,2, \ldots, s, \\
& k=1,2, \ldots, n
\end{aligned}
$$

ただし，lex-min は䑙其式最小化を意味する。また， $\boldsymbol{u}^{K}=\left(u_{1}^{K}, u_{2}^{K}, \ldots, u_{m}^{K}\right), \boldsymbol{v}^{K}=\left(v_{1}^{K}, v_{2}^{K}, \ldots, v_{s}^{K}\right)$ とする.

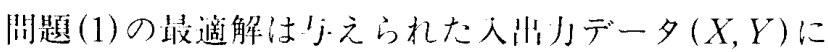
依保するので, $\left(\hat{\theta}_{K}(X, Y), \hat{\lambda}(X, Y), \mathfrak{a}^{K}(X, Y), \hat{\boldsymbol{v}}^{k}\right.$ $(X, Y))$ と記す。ただし，六忚」デー夕 $(X, Y)$ は㑬を とるもの，すなわち， $X>O_{m}^{n}, Y>O_{s}^{n}$ と伙过子る。ここ で， $O_{m}^{n}$ は $m \times n$ の零行列である。以後，簡使のため，

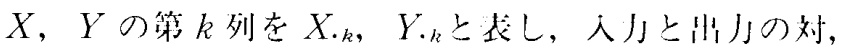
$\left(X,_{k}, Y_{*_{k}}\right)$ を活動と响心゙。

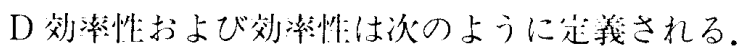

定義1 $\hat{\theta}_{K}(X, Y)=1$ であるとき, $D M U_{K}$ は $\left.\mathrm{D}\right)$ 攽維似 であるという。また, $\hat{\theta}_{K}(X, Y) を D M U_{K}$ の D 效摔做と いう。

定義2 $\hat{\theta}_{K}(X, Y)=1$ かつ $\hat{\boldsymbol{u}}^{K}(X, Y)=\mathbf{0}, \hat{\boldsymbol{v}}^{K}(X, Y)=$

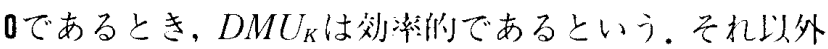
のとき，非効澵的であるという。

次の尖理は, $D M U_{K}$ の活動 $\left(X_{*_{K}}, Y_{\cdot_{K}}\right)$ に扔いて, 人J
を $\hat{\theta}_{K}(X, Y)$ 倍に繀小し, 余剩 $\hat{\boldsymbol{u}}^{K}(X, Y)$ を除去すると ともに，出打に不足分 $\boldsymbol{v}^{K}(X, Y)$ を追加すれば，效摔的 な活動になることを示している。

定理1 $D M U_{K}$ が非効㻭的であるとき， $X_{. K}^{\text {new }}=\hat{\theta}_{K}(X$, $Y) X_{{ }_{K}}-\hat{\boldsymbol{u}}^{K}(X, Y), Y_{{ }_{K}}^{\text {new }}=Y_{{ }_{K}}+\hat{\boldsymbol{v}}^{K}(X, Y)$ と变更 すれば， $D M U_{K}$ の活動は效摔的になる。

$\hat{\theta}_{K}(X, Y), \hat{\lambda}(X, Y), \hat{\boldsymbol{u}}^{k}(X, Y), \hat{\boldsymbol{v}}^{K}(X, Y)$ を写像 とみなし，その性質を議論しよう。次の補題が成立す る.

補題1 $\hat{\lambda}(X, Y)=\left(\hat{\lambda}_{1}(X, Y), \hat{\lambda}_{2}(X, Y), \ldots, \hat{\lambda}_{n}(X\right.$, $Y)$ )とするとき，次式が成付する。

$$
\hat{\lambda}_{K}(X, Y) \leq \hat{\theta}_{K}(X, Y)
$$

さらに, $\hat{\theta}_{K}(X, Y)=1 の$ ときに限り, $\hat{\lambda}_{K}(X, Y)>0$ とな る.

（証明）閆題(1)の制約条作より，式(2)は明らかであ る。また，開題(1)より明らかに, $\hat{\theta}_{K}(X, Y) \leq 1$ とな

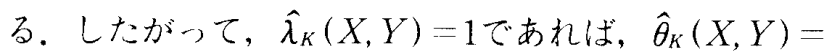
1 となる。 $0<\hat{\lambda}_{K}(X, Y)<1 て ゙ あ る と き, \hat{\theta}_{K}(X, Y)<1 て ゙$ あると似这しよj。このとき， $\hat{\theta}_{K}=\left(\hat{\theta}_{K}(X, Y)-\hat{\lambda}_{K}(X\right.$, $Y)) /\left(1-\hat{\lambda}_{K}(X, Y)\right), \hat{\lambda}_{k}=\hat{\lambda}_{k}(X, Y) /\left(1-\hat{\lambda}_{K}(X\right.$, $Y)), \quad k \neq K, \quad \hat{\lambda}_{k}=0, \quad \hat{\boldsymbol{u}}^{K}=\hat{\boldsymbol{a}}^{K}(X, Y) /\left(1-\hat{\lambda}_{K}(X\right.$, $Y)), \hat{\boldsymbol{v}}^{K}=\hat{\boldsymbol{v}}^{K}(X, Y) /\left(1-\hat{\lambda}_{K}(X, Y)\right)$ により定義さ れる解 $\left(\hat{\theta}_{K}, \hat{\lambda}, \hat{u}^{K}, \hat{v}^{K}\right)$ は問題(1)の坚行叮能解とな

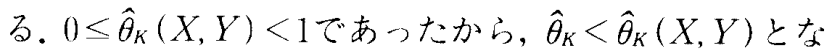
り, $\hat{\theta}_{K}(X, Y)$ の最畄性に牙盾する。したがって, $\hat{\lambda}_{K}(X$, $Y)>0$ であ机ば， $\hat{\theta}_{K}(X, Y)=1$ となる。

補題1を川いると，次の定理が訢明できる。

定理2 $\hat{\theta}_{K}(X, Y)$ は, $X>O_{m}^{n}, Y>O_{s}^{n}$ に関して連続な 闺数である。ま心， $\hat{\theta}_{K}(X, Y)$ は， $X_{K_{K}}$ に関して非增加， $Y_{\cdot K}$ に関して非減少であり, $X_{\cdot_{k}}, k \neq K$ に関して非減 少， $Y_{\cdot}, k \neq K$ に関して非增加である。

（証明）後半は，補題1より突易に示せる。前半を証明し よう。この诸明に, Hogan[6]の定理を用いる，X> $O_{m}^{n}, \quad \hat{\theta}_{K}(X, Y) \leq 1$ 上り, $\hat{\theta}_{K}(X, Y)$ は $\boldsymbol{u}^{K}, \boldsymbol{v}^{K}$ 除き，い くつかの片な制約条件を加えた次の線形部画開題 $P(X, Y)$ の浐適俌でもある。

minimize $f\left(\theta_{K}, \lambda: X, Y\right)=\theta_{K}$ subject to

$$
\begin{aligned}
& \boldsymbol{g}_{1}\left(\theta_{K}, \lambda: X, Y\right)=X \boldsymbol{\lambda}-\theta_{K} X \cdot_{K} \leq \mathbf{0}, \\
& \boldsymbol{g}_{2}\left(\theta_{K}, \lambda: X, Y\right)=Y \cdot \cdot_{K}-Y \lambda \leq \mathbf{0}, \\
& g_{3 k}\left(\theta_{K}, \lambda: X, Y\right)=x_{i k} \lambda_{k}-x_{i K} \leq 0 \\
& g_{4 k}\left(\theta_{K}, \lambda: X, Y\right)=-\lambda_{k} \leq 0
\end{aligned}
$$




$$
\begin{aligned}
& g_{5}\left(\theta_{K}, \lambda: X, Y\right)=\theta_{K}-1 \leq 0, \\
& g_{6}\left(\theta_{K}, \lambda: X, Y\right)=-\theta_{K} \leq 0, \\
& \quad k=1,2, \ldots, n
\end{aligned}
$$

ただし， $1 \leq i \leq m$ は任意に選ばれた自然数である。簡 便のため, $S(X, Y)$ を $P(X, Y)$ の実行可能集合, $\boldsymbol{g}_{j}$ $\left(\theta_{K}, \lambda: X, Y\right)=\left(g_{j 1}\left(\theta_{K}, \lambda: X, Y\right), \ldots, g_{j n}\left(\theta_{K}, \lambda:\right.\right.$ $X, Y))^{\mathrm{T}}, j=3,4$ とする。明らかに, $f, \boldsymbol{g}_{j}, j=1,2,3,4$ および $g_{j}, j=5,6$ は $\theta_{K}, \lambda, X, Y$ に関して連続とな る. $X>O_{m}^{n}, \quad Y>O_{s}^{n}$ る任意の $(X, Y)$ に対して, $\boldsymbol{g}_{j}$, $j=1,2,3,4$ おび $g_{j}, j=5,6$ は $\theta_{K}$ およ゙゙んに関して凸 (厳密には，線形)である. $X>O_{m}^{n}, Y>O_{s}^{n}$ る任意の $(X, Y)$ に対して, $S(X, Y)$ はコンパクトであるので, $S(X, Y)$ は $(X, Y)$ に関して一様コンパクトである。さ らに, $X>O_{m}^{n}, \quad Y>O_{s}^{n}$ る任意の $(X, Y)$ に対して， $\left\{\left(\theta_{K}, \lambda\right) \mid \boldsymbol{g}_{j}\left(\theta_{K}, \lambda: X, Y\right)<\mathbf{0}, j=1,2,3,4, g_{j}\left(\theta_{K}, \lambda:\right.\right.$ $X, Y)<0, j=5,6\} \neq \emptyset$ となる.したがって, Hogan $[6]$ の定理7, 10,12より， $\hat{\theta}_{K}(X, Y)$ は連続になる。

定理3 $-\sum_{i=1}^{m} \hat{u}_{i}^{K}(X, Y)-\sum_{i}^{p} \hat{v}_{j}^{K}(X, Y)$ は, $X \cdot$. $_{K}$ に関し て非増加, ${ }^{i=1}{ }_{._{K}}$ に関して非減少である。また， $X_{\cdot_{k}}, k \neq$ $K$ に関して非減少， $Y_{\cdot k}, k \neq K$ に関して非增加であ る.

（証明）補題1より容易に示せる.

\section{3. ファジィ入出カデータ}

各DMUの入出力データが明確に得られない場合 や，入出力データが変動して抢り変動範囲が明確にわ からない場合には, 入力デー夕 $x_{i k}$ るいは出力デー夕 $y_{j k}$ をァジィ数[7]として, 取り扱った力が現突的で ある、このような観点から，ファジィ入力デー夕 $\widetilde{x}_{i k}$, ファジィ出力データ $\tilde{y}_{j k}$ に対する DEAについて考察 する.なお，各ファジィ入出力デー夕 $\tilde{x}_{i k}, \tilde{y}_{j k}$ は，それ ぞれ, L-R ファジイ数 $[7]\left(x_{i k}^{\mathrm{L}}, x_{i k}^{\mathrm{R}}, \alpha_{i k}^{\mathrm{L}}, \alpha_{i k}^{\mathrm{R}}\right)_{L_{i k}^{\mathrm{x}} R_{i k}^{\mathrm{x}}}, \quad\left(y_{j k}^{\mathrm{L}}\right.$, $\left.y_{j k}^{\mathrm{R}}, \beta_{j k}^{\mathrm{L}}, \beta_{j k}^{\mathrm{R}}\right)_{L_{j k}^{y} R_{j k}^{y}}$ で表され, 次のメンバシップ関数 $\mu_{\tilde{x}_{i k}}$, $\mu_{\tilde{y}_{j k}}$ をつとする.

$$
\mu_{\tilde{x}_{i k}}(r)=\left\{\begin{array}{cl}
L_{i k}^{\mathrm{x}}\left(\frac{x_{i k}^{\mathrm{L}}-r}{\alpha_{i k}^{\mathrm{L}}}\right) ; & r<x_{i k}^{\mathrm{L}} \\
1 ; & x_{i k}^{\mathrm{L}} \leq r \leq x_{i k}^{\mathrm{R}} \\
\left.R_{i k}^{\mathrm{x}}\left(\frac{r-x_{i k}^{\mathrm{R}}}{\alpha_{i k}^{\mathrm{R}}}\right)\right) & ; r>x_{i k}^{\mathrm{R}}
\end{array}\right.
$$

$$
\mu_{\tilde{y}_{j k}}(r)=\left\{\begin{array}{cl}
L_{j k}^{\mathrm{y}}\left(\frac{y_{j k}^{\mathrm{L}}-r}{\beta_{j k}^{\mathrm{L}}}\right) ; & r<y_{j k}^{\mathrm{L}} \\
1 ; & y_{j k}^{\mathrm{L}} \leq r \leq y_{j k}^{\mathrm{R}} \\
R_{j k}^{\mathrm{y}}\left(\frac{r-y_{j k}^{\mathrm{R}}}{\beta_{j k}^{\mathrm{R}}}\right) ; & r>y_{j k}^{\mathrm{R}}
\end{array}\right.
$$

ここで， $L_{i k}^{\mathrm{x}}, R_{i k}^{\mathrm{x}}, L_{j k}^{\mathrm{y}}, R_{j k}^{\mathrm{y}}$ は次のように定義される型関 数であり， $L_{i k}^{\mathrm{x}}, L_{j k}^{\mathrm{y}}$ は左側の形状を規定し, $R_{i k}^{\mathrm{x}}, R_{j k}^{\mathrm{y}}$ は布 側の形状を規定している. 型関数 $L:[0,+\infty) \rightarrow[0,1]$ とは $L(0)=1, \lim _{r \rightarrow+\infty} L(r)=0$ なる上半連続な非增 加関数である. また， $x_{i k}^{\mathrm{L}}, y_{j k}^{\mathrm{L}}$ はメンバシップ值が1とな る値の下限值を示し， $x_{i k}^{\mathrm{R}}, y_{j k}^{\mathrm{R}}$ は上限值を示している. $\alpha_{i k}^{\mathrm{L}}, \beta_{j k}^{\mathrm{L}}$ は左側の広がりを， $\alpha_{i k}^{\mathrm{R}}, \beta_{j k}^{\mathrm{R}}$ は右側の㕕がりを 定めている。通常の DEA で， $x_{i k}, y_{j k}$ が正であると仮定 していなことに対応し， $\tilde{x}_{i k}, \widetilde{y}_{j k}$ に対して次式を仮定 する。

$$
\left.\begin{array}{l}
\exists \varepsilon_{i k}>0, \quad \forall r \leq \varepsilon_{i k} ; \mu_{\widetilde{x}_{i k}}(r)=0 \\
\exists \varepsilon_{j k}>0, \quad \forall r \leq \varepsilon_{j k} ; \mu_{\bar{y}_{j k}}(r)=0
\end{array}\right\}
$$

便穵上，ファジィ入出力デー夕 $\widetilde{x}_{i k}, \widetilde{y}_{j k}$ を成分とする 行列をそれぞれ， $\widetilde{X}=\left(\tilde{x}_{i k}\right), \tilde{Y}=\left(\tilde{y}_{j k}\right)$ とし, 次のメン バシップ関数で定める.

$$
\begin{aligned}
& \mu_{\widetilde{X}}(X)=\min _{\substack{i=1,2, \ldots, m \\
k=1,2, \ldots, n}} \mu_{\widetilde{x}_{i k}}\left(x_{i k}\right) \\
& \mu_{\widetilde{Y}}(Y)=\min _{\substack{j=1,2, \ldots, s \\
k=1,2, \ldots, n}} \mu_{\widetilde{y}_{j k}}\left(y_{j k}\right)
\end{aligned}
$$

\section{4. 拡張原理とファジィロ効率值}

問題 (1)の最適值 $\hat{\theta}_{K}(X, Y)$ は入出力デー夕 $(X, Y)$ に対するある写像の像と考えることができる。この観 点から, 拡張原理 [7]を用いて, ファジィ入出力デー夕 $(\widetilde{X}, \widetilde{Y})$ に対する像として，D效率值のファジィ集合 $\hat{\theta}_{K}(\tilde{X}, \widetilde{Y})$ を定めることができる.まず, 拡張原理とそ の性質 $[7]$ にいて述べる.

搪張原理は次のように書ける。

定義3 写像 $f: \Omega_{1} \times \Omega_{2} \times \cdots \times \Omega_{q} \rightarrow \Xi$ 与えられたと き, $\Omega_{i}$ ト.のファジイ集合 $\tilde{A}_{i}, i=1,2, \ldots, q$ の $f$ にる 像 $f\left(\widetilde{A_{1}}, \widetilde{A_{2}}, \ldots, \widetilde{A_{q}}\right)$ は, 次のメンバシップ関数をも つファジィ集合として定められる。

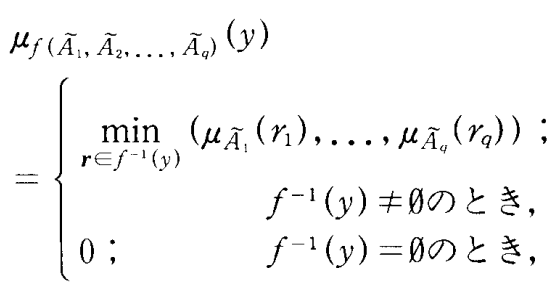


ただし， $\boldsymbol{r}=\left(r_{1}, r_{2}, \ldots, r_{q}\right)$ あ゙あ,$f^{-1}(y)$ は $f$ 逆像 で，次のように定義される。

$$
f^{-1}(y)=\{\boldsymbol{r} \mid f(\boldsymbol{r})=y\}
$$

特に, $\Omega_{1}=\Omega_{2}=\cdots=\Omega_{q}=\boldsymbol{\Xi}=\mathbf{R}$ のとき，拡張原理に 関して，以下の定理が成立する[7]。

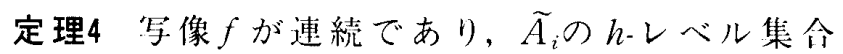
$\left[\tilde{A}_{i}\right]_{h}=\left\{\omega \mid \mu_{\tilde{A}_{i}}(\omega) \geq h\right\}$ が任意の $h \in(0,1]$ に関して 有界閉集合となるとき，次式が成计する。

$$
\left[f\left(\tilde{A}_{1}, \tilde{A_{2}}, \ldots, \tilde{A_{q}}\right)\right]_{h}=f\left(\left[\tilde{A}_{1}\right]_{h},\left[\tilde{A_{2}}\right]_{h}, \ldots,\left[\tilde{A_{q}}\right]_{h}\right)
$$

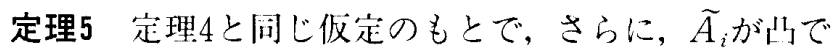
あり, 写像 $f$ が $x_{1}, \ldots, x_{q^{\prime}}$ に関して非減少, $x_{q^{\prime}+1}, \ldots, x_{q}$ に 関して非增加であるとき，

$$
\left[f\left(\widetilde{A_{1}}, \widetilde{A_{2}}, \ldots, \widetilde{A_{q}}\right)\right]_{h}=\left[f^{\mathrm{L}}(h), f^{\mathrm{R}}(h)\right]
$$

が成立する。ただし， $q^{\prime} \leq q$ とし，式(11)の布巡の閉区 間の上:下限值は，次のように定義される。

$f^{\mathrm{L}}(h)=f\left(a_{1}^{\mathrm{L}}(h), \ldots, a_{q^{\prime}}^{\mathrm{L}}(h), a_{q^{\prime}+1}^{\mathrm{R}}(h), \ldots, a_{q}^{\mathrm{R}}(h)\right)$

$f^{\mathrm{R}}(h)=f\left(a_{1}^{\mathrm{R}}(h), \ldots, a_{q^{\prime}}^{\mathrm{R}}(h), a_{q^{\prime}+1}^{\mathrm{L}}(h), \ldots, a_{q}^{\mathrm{l}}(h)\right)$

ここで, $a_{i}^{\mathrm{l}}(h), \quad a_{i}^{\mathrm{R}}(h)$ は $\left[\tilde{A}_{i}\right]_{h}$ の下限值と卜限值であ る、 $\widetilde{A_{i}}$ がいであり, $\left[\tilde{A}_{i}\right]_{h}$ は閉区間となるので, $\left[\tilde{A}_{i}\right]_{h}=$ $\left[a_{i}^{\mathrm{L}}(h), a_{i}^{\mathrm{R}}(h)\right]$ と表せる.

さて, D 刘摔值のファジィ集合について議論しよう。 定理2より，入出力デー夕から D 效率值への写像 $\hat{\theta}_{K}$

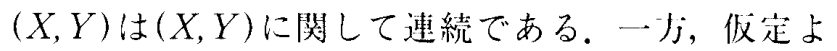
り，ファジィデータ $\tilde{x}_{i k}, \tilde{y}_{j k}$ は山で, 任意の $h \in(0,1]$ に対して $\left[\widetilde{x}_{i k}\right]_{h},\left[\tilde{y}_{j k}\right]_{h}$ は标界閉集合となる.したがっ て, 定理 $2,4,5$ 上り,

$$
\begin{array}{r}
{\left[\hat{\theta}_{K}(\tilde{X}, \tilde{Y})\right]_{h}=\left[\hat{\theta}_{K}\left(X^{\mathrm{L}}(h: K), Y^{\mathrm{R}}(h: K)\right),\right.} \\
\left.\hat{\theta}_{K}\left(X^{\mathrm{R}}(h: K), Y^{\mathrm{L}}(h: K)\right)\right]
\end{array}
$$

が成立する。ただし，

$$
\begin{aligned}
& X^{\mathrm{L}}(h: K)=\left(X_{{ }_{1}}^{\mathrm{L}}(h), \ldots, X_{{ }^{\prime}-1}(h),\right. \\
& \left.X^{\mathrm{R}}{ }_{K}(h), X_{\cdot_{K+1}}^{\mathrm{L}}(h), \ldots, X{ }^{!_{n}}(h)\right) \\
& X^{\mathrm{R}}(h: K)=\left(X_{{ }^{\mathrm{R}}}^{\mathrm{R}}(h), \ldots, X_{{ }^{\mathrm{R}-1}}^{\mathrm{R}}(h)\right. \text {, } \\
& \left.X_{{ }^{\prime}}^{\mathrm{L}}(h), X_{{ }^{\mathrm{R}}{ }^{\mathrm{R}+1}}(h), \ldots, X^{\mathrm{R}}{ }_{n}(h)\right)
\end{aligned}
$$

で, $X_{*_{k}}(h), X_{{ }_{k}}^{\mathrm{k}}(h)$ は, それぞ, 次の $(i, k)$ 成分 $X_{i k}^{\mathrm{L}}(h), X_{i k}^{\mathrm{R}}(h)$ で構成される行列 $X^{\mathrm{L}} \cdot(h)=$ $\left(X_{i k}^{\mathrm{L}}(h)\right), X^{\mathrm{R}}(h)=\left(X_{i k}^{\mathrm{R}}(h)\right)$ の第 $k$ 列である.

$$
\begin{aligned}
& X_{i k}^{\mathrm{L}}(h)=x_{i k}^{\mathrm{L}}-\alpha_{i k}^{\mathrm{I}}\left(L_{i k}^{\mathrm{x}}\right)^{(-1)}(h) \\
& X_{i k}^{\mathrm{R}}(h)=x_{i k}^{\mathrm{R}}+\alpha_{i k}^{\mathrm{R}}\left(R_{i k}^{\mathrm{x}}\right)^{(-1)}(h)
\end{aligned}
$$

$$
\begin{aligned}
& \left(L_{i k}^{\mathrm{x}}\right)^{(-1)}(h)=\sup \left\{r \mid L_{i k}^{\mathrm{x}}(r) \geq h\right\} \\
& \left(R_{i k}^{\mathrm{x}}\right)^{(-1)}(h)=\sup \left\{r \mid R_{i k}^{\mathrm{x}}(r) \geq h\right\}
\end{aligned}
$$

と定義される。 $Y_{{ }_{k}}^{\mathrm{L}}(h), Y_{{ }_{k}}^{\mathrm{R}}(h)$ についても间様に定如 られる。

式(14)は，閉区間となる $\hat{\theta}_{K}(\widetilde{X}, \widetilde{Y})$ の $h$ レベル集命 $\left[\hat{\theta}_{K}(\widetilde{X}, \widetilde{Y})\right]_{h}$ の下限值が, 入力デ一タに関しては, $k \neq$ $K$ に刘して h-レベル集合 $\left[\tilde{x}_{i k}\right]_{h}$ の下限值を，Kに対 してはhーレベル集合 $\left[\tilde{x}_{i K}\right]_{h}$ の上限僧を代入し, 出力デ

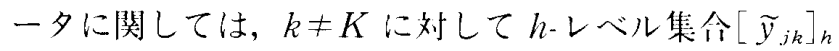
の、限值を， $K$ に対しては $h$-レベル集合 $\left[\tilde{y}_{j K}\right]_{h}$ のト 限值を代人寸れば得られることをホしている。また，

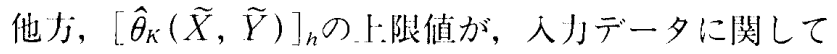
は， $k \neq K$ に対して $h$-レベル集合 $\left[\widetilde{x}_{i k}\right]_{h}$ のI:限㑤を， $K$ に対しては $h$ レベル集合 $\left[\tilde{x}_{i K}\right]_{h}$ のト限嗐を代入し， 出打デー夕に関しては, $k \neq K$ に対して $h$ ーレベル集合 $\left[\widetilde{y}_{j k}\right]_{h}$ ア卜限值を，Kに対してはh-レベル集合 $\left[\tilde{y}_{j K}\right]_{h}$ のト限值を代入すれば得られることも亦して いる。これらは， $[\widetilde{X}]_{h},[\widetilde{Y}]_{h}$ の範䎴队で，入虭少デー 夕 $(X, Y)$ を $\left[\hat{\theta}_{K}(\widetilde{X}, \widetilde{Y})\right]_{n}$ のト限僧に㘣しては $D M U_{K}$ にとって最も不利となるように，|限值に関しては最 も侍利になるように盗奴ことを衣して打り，消感に 命致している。

分解原理 [7]卡り，

$$
\begin{aligned}
& \mu_{\hat{\theta}_{K}(\tilde{X}, \tilde{Y})}(r) \\
& =\left\{\begin{array}{c}
\sup \left\{h \in(0,1] \mid r \in\left[\hat{\theta}_{K}(\tilde{X}, \widetilde{Y})\right]_{h}\right\} ; \\
\ddot{\exists} h, r \in\left[\hat{\theta}_{K}(\widetilde{X}, \widetilde{Y})\right]_{h} \sigma と き, \\
0 ; \text { その)他, }
\end{array}\right.
\end{aligned}
$$

となるので, 一分多くの h-レベル集合 $\left[\hat{\theta}_{K}(\tilde{X}, \widetilde{Y})\right]_{h}$ を 求坖により，ファジィ集令 $\hat{\theta}_{K}(\widetilde{X}, \tilde{Y})$ を近似寸 ることができる. なお， $\left[\hat{\theta}_{K}(\widetilde{X}, \widetilde{Y})\right]_{h} の$ たト限值は，

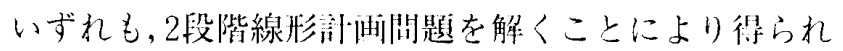
る.

\section{5. 可能性理論に基づく効率性分析}

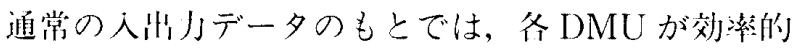
であるか垈かを二做的に判断することができる。一う， ファジィ人蛙力データのもとでは, DMUが效摔的で あるか不かを一值的に判断することができず，效䜌的 である度命が求められる。これらの度命は叮能性測度 [7]と必然性測度 $[7]$ により定めることができる。

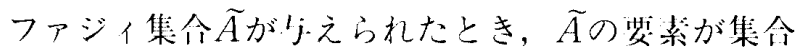
$B$ に州属古る川能性の度合 $\Pi_{\bar{A}}(B)$ と必然性の度合 $\mathrm{N}_{\widetilde{A}}(B)$ は次のように定龵される。

なお，擬逆関数 $\left(L_{i k}^{\mathrm{X}}\right)^{(-1)},\left(R_{i k}^{\mathrm{x}}\right)^{(-1)}$ は, 


$$
\begin{aligned}
& \Pi_{\widetilde{A}}(B)=\left\{\begin{array}{l}
\sup _{r \in B} \mu_{\widetilde{A}}(r) ; B \neq \emptyset \\
0 ; B=\emptyset
\end{array}\right. \\
& \mathrm{N}_{\widetilde{A}}(B)=\left\{\begin{array}{l}
\inf _{r \in B}\left(1-\mu_{\widetilde{A}}(r)\right) ; B \neq \Omega \\
1 ; B=\Omega
\end{array}\right.
\end{aligned}
$$

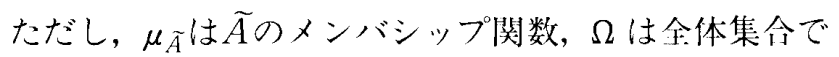
ある。

可能性測度 П, 必然性測度 N について, 次式が成市。 する。

$$
\begin{aligned}
& \mathrm{N}_{\widetilde{A}}(B)>0 \Longrightarrow \Pi_{\widetilde{A}}(B)=1 \\
& \Pi_{\widetilde{A}}(B)>h \Longleftrightarrow(\tilde{A})_{h} \cap B \neq \emptyset \\
& \mathrm{N}_{\widetilde{A}}(B) \geq h>0 \Longleftrightarrow(\widetilde{A})_{1-h} \subseteq B
\end{aligned}
$$

ただし， $(\widetilde{A})_{h}$ はファジイ集合 $\widetilde{A} の$ 強 $h$ ・レベル集合で, $(\widetilde{A})_{h}=\left\{r \mid \mu_{\tilde{A}}(r)>h\right\}$ と定放れる.

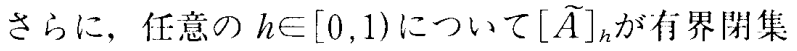
合であり， $B$ が閉集合である埸合には，

$$
\begin{aligned}
& \Pi_{\tilde{A}}(B) \geq h>0 \Longleftrightarrow[\tilde{A}]_{h} \cap B \neq \emptyset \\
& \mathrm{N}_{\tilde{A}}(B) \geq h>0 \Longleftrightarrow \operatorname{cl}(\tilde{A})_{1-h} \subseteq B
\end{aligned}
$$

が成凉する。こで， $\mathrm{cl} D$ は集令 $D$ の閉包である。

$\mathrm{DMU}_{K}$ が効率的になる活動 $(X, Y)$ の集合 $E F_{K}$ は,

$$
\begin{aligned}
E F_{K}=\{ & (X, Y) \geq\left(E_{x}, E_{y}\right) \mid \hat{\theta}_{K}(X, Y)=1, \\
& \left.\hat{\boldsymbol{u}}^{K}(X, Y)=\mathbf{0}, \hat{\boldsymbol{v}}^{K}(X, Y)=\mathbf{0}\right\}
\end{aligned}
$$

と定義できるから，式 (22)，(23)の叮能性测度, 必然 性测度より，DMUKが効摔的である叮能性の度合と必 然性の度合を $\Pi_{(\tilde{X}, \tilde{Y})}\left(E F_{K}\right)$ および $\mathrm{N}_{(\tilde{X}, \tilde{Y})}\left(E F_{K}\right)$ によ り定めることができる。ただし， $E_{x}=\left(\varepsilon_{i k}\right), E_{y}=\left(\varepsilon_{j k}\right)$ である.特に, $\Pi_{(\tilde{X}, \tilde{Y})}\left(E F_{K}\right)=0$ であるときには, 式 $(25)$ より, $\left((\widetilde{X})_{0} \times(\widetilde{Y})_{0}\right) \cap E F_{K}=\emptyset$ より, $\mu_{\tilde{X}}(X)>0$, $\mu_{\tilde{Y}}(Y)>0$ なる任意の入出力デー夕 $(X, Y)$ に対して, $D M U_{K}$ が效率的でない，才なわち， $D M U_{K}$ が效㻭的で ありえないこと，あるいは，常に効率的でないことを 亦す。一方, $\mathrm{N}_{(\tilde{X}, \tilde{Y})}\left(E F_{K}\right)=1$ であるときには, 式 (26) より, $\left((\widetilde{X})_{0} \times(\widetilde{Y})_{0}\right) \subseteq E F_{K}$ となり, $\mu_{\widetilde{X}}(X)>0$, $\mu_{\tilde{Y}}(Y)>0$ なる任意の入出力デー夕 $(X, Y)$ に対して, $D M U_{K}$ が效率的である。古なわち， $D M U_{K}$ が必ず效摔 的であること，あるいは，常に效率的であることを示 す.さらに, $\Pi_{(\tilde{X}, \tilde{Y})}\left(E F_{K}\right)>0 て ゙ あ る と き に は ， D M U_{K}$ がある程度(可能性の度合 $\Pi_{(\tilde{X}, \tilde{Y})}\left(E F_{K}\right)$ で) 效涞的で ありうることを表し， $\mathrm{N}_{(\tilde{X}, \tilde{Y})}\left(E F_{K}\right)>0$ であるときに は，DMU $U_{K}$ がある程度 (必然性の度合 $\mathrm{N}_{(\bar{X}, \bar{Y})}\left(E F_{K}\right)$ で) 效影的であると確信できることを表す。

以下では，任意の $h \in(0,1]$ につて, $\Pi_{(\bar{X}, \tilde{Y})}\left(E F_{K}\right)$ $\geq h$ あるいは $\mathrm{N}_{(\tilde{X}, \tilde{Y})}\left(E F_{K}\right) \geq h$ であるか㔻かを调べ
る方法，拉よび，そうでない場合にそうなるために必 要な收善案の一つを求好る方法を議論寸る。しかし， 式 (25), (26)より,

$$
\begin{aligned}
\left([\tilde{X}]_{h} \times[\tilde{Y}]_{h}\right) \cap E F_{K} & \neq \emptyset \\
& \Longrightarrow \Pi_{(\tilde{X}, \tilde{Y})}\left(E F_{K}\right) \geq h \\
\operatorname{cl}\left((\tilde{X})_{1-h} \times(\tilde{Y})_{1-h}\right) & \subseteq E F_{K} \\
& \Longrightarrow \mathrm{N}_{(\tilde{X}, \tilde{Y})}\left(E F_{K}\right) \geq h
\end{aligned}
$$

は成斿するが, $E F_{K}$ が閉集合でないため,これらの逆は 成的しない，その代わり，任意の $\varepsilon>0$ に対して，次式 が成行する。

$$
\begin{aligned}
\Pi_{(\tilde{X}, \tilde{Y})}\left(E F_{K}\right) & \geq h \\
& \Longrightarrow\left([\tilde{X}]_{h-\varepsilon} \times[\tilde{Y}]_{h-\varepsilon}\right) \cap E F_{K} \neq \emptyset \\
\mathrm{N}_{(\tilde{X}, \tilde{Y})}\left(E F_{K}\right) \geq h & \geq\left((\tilde{X})_{1-h} \times(\tilde{Y})_{1-h}\right) \subseteq E F_{K}
\end{aligned}
$$

したがって，綮密に $\Pi_{(\widetilde{X}, \widetilde{Y})}\left(E F_{K}\right) \geq h$ および $\mathrm{N}_{(\widetilde{X}, \tilde{Y})}$ $\left(E F_{K}\right) \geq h$ を議論する代わりに，それらを幾分強めた

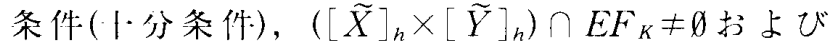
$\operatorname{cl}\left((\widetilde{X})_{1-h} \times(\widetilde{Y})_{1-h}\right) \subseteq E F_{K}$ の成枌を議棆することに しよう.

$$
\begin{aligned}
& \left(X_{1}, Y_{1}\right) \leq\left(X_{2}, Y_{2}\right) \text { について } \\
& \quad\left[\left(X_{1}, Y_{1}\right),\left(X_{2}, Y_{2}\right)\right] \\
& \quad=\left\{(X, Y) \mid\left(X_{1}, Y_{1}\right) \leq(X, Y) \leq\left(X_{2}, Y_{2}\right)\right\}
\end{aligned}
$$

と定義すれば， $\left[\tilde{x}_{i k}\right]_{h} ，\left[\tilde{y}_{j k}\right]_{h}$ は行界閉集合となること より,

$$
\begin{aligned}
& \left([\tilde{X}]_{h} \times[\tilde{Y}]_{h}\right) \\
& \quad=\left[\left(X^{\mathrm{L}}(h), Y^{\mathrm{L}}(h)\right),\left(X^{\mathrm{R}}(h), Y^{\mathrm{R}}(h)\right)\right]
\end{aligned}
$$

と㫪ける。また， $(X, Y) \in E F_{K} は \hat{\theta}(X, Y)=1, \hat{\boldsymbol{u}}^{K}(X$, $Y)=\mathbf{0}, \hat{\boldsymbol{v}}^{K}(X, Y)=\mathbf{0}$ が成的することを表すので, 尘 埋2より次式が得られる。

$$
\begin{aligned}
& \left([\tilde{X}]_{h} \times[\tilde{Y}]_{h}\right) \cap E F_{K} \neq \emptyset \\
& \Longleftrightarrow\left\{\begin{array}{l}
\hat{\theta}_{K}\left(X^{\mathrm{R}}(h: K), Y^{\mathrm{L}}(h: K)\right)=1, \\
\hat{\boldsymbol{u}}^{K}\left(X^{\mathrm{R}}(h: K), Y^{\mathrm{I}}(h: K)\right)=\mathbf{0}, \\
\hat{\boldsymbol{v}}^{K}\left(X^{\mathrm{R}}(h: K), Y^{\mathrm{I}}(h: K)\right)=\mathbf{0}
\end{array}\right.
\end{aligned}
$$

したがって, $\Pi_{(\tilde{X}, \tilde{Y})}\left(E F_{K}\right) \geq h$ の分条件は, 入出打デ 一夕を $\left(X^{\mathrm{R}}(h: K), Y^{\mathrm{L}}(h: K)\right)$ として, 開題 (1) を解 けば容易に確認できる。

いま，式(36)の存辺が成立しないとすると， $\Pi_{(\tilde{X}, \tilde{Y})}$ $\left(E F_{K}\right) \geq h$ が成不すると断言できない.しかし，定理1 より, $D M U_{K}$ の活動 $\left(X \cdot_{K}, Y_{._{K}}\right)$ を次式で定義される $\left(X_{\cdot K}^{\text {new }}, Y_{\cdot K}^{\text {new }}\right)$ に改善すれば, $\left.\Pi_{(\tilde{X}}, \tilde{Y}\right)\left(E F_{K}\right) \geq h$ が成市. する，すなわち， $D M U_{K}$ は四能性の度合 $h$ 以上で效摔 的であると断舒でる。 


$$
\begin{aligned}
& \widetilde{X}_{\cdot K}^{\text {new }}=\hat{\theta}\left(X^{\mathrm{R}}(h: K), Y^{\mathrm{l}}(h: K)\right) \widetilde{X}_{\cdot K} \\
& -\hat{\boldsymbol{a}}\left(X^{\mathrm{R}}(h: K), Y^{\mathrm{I}}(h: K)\right) \\
& \tilde{Y}_{\cdot K}^{\text {new }}=\tilde{Y}_{\cdot K}+\hat{v}\left(X^{\mathrm{R}}(h: K), Y^{\mathrm{l}} \cdot(h: K)\right)
\end{aligned}
$$

一) $j$, 擬遡関数 $\left(L_{i k}^{\mathrm{x}}\right)^{<-1>},\left(R_{i k}^{\mathrm{x}}\right)^{<-1>}$ を

$$
\begin{aligned}
& \left(L_{i k}^{\mathrm{x}}\right)^{<-1>}(h)=\sup \left\{r \mid L_{i k}^{\mathrm{x}}(r)>h\right\} \\
& \left(R_{i k}^{\mathrm{x}}\right)^{<-1>}(h)=\sup \left\{r \mid R_{i k}^{\mathrm{x}}(r)>h\right\}
\end{aligned}
$$

と定義し，

$$
\begin{aligned}
& X_{i k}^{\mathrm{L}}(h)=x_{i k}^{\mathrm{L}}-\alpha_{i k}^{\mathrm{L}}\left(L_{i k}^{\mathrm{x}}\right)^{<-1>}(h) \\
& X_{i k}^{\mathrm{R}}(h)=x_{i k}^{\mathrm{R}}+\alpha_{i k}^{\mathrm{R}}\left(R_{i k}^{\mathrm{x}}\right)^{<-1>}(h)
\end{aligned}
$$

を用いて, $X^{\bar{L}}(h)=\left(X_{i k}^{\bar{L}}(h)\right), X^{\overline{\mathrm{R}}}(h)=\left(X_{i k}^{\overline{\mathrm{R}}}(h)\right)$ と定 める。 $Y^{\mathrm{L}}(h), Y^{\overline{\mathrm{R}}}(h)$ も间㥞に筐好ると，

$$
\begin{aligned}
& \operatorname{cl}\left((\tilde{X})_{1-h} \times(\widetilde{Y})_{1-h}\right) \\
& =\left[\left(X^{\mathrm{L}}(1-h), Y^{\mathrm{L}}(1-h)\right),\right. \\
& \left.\quad\left(X^{\mathrm{R}}(1-h), Y^{\mathrm{R}}(1-h)\right)\right]
\end{aligned}
$$

となる。式(15)，（16）と闬様に，

$$
\begin{aligned}
X^{\mathrm{L}}(h: K)= & \left(X_{\cdot 1}^{\mathrm{L}}(h), \ldots, X_{\cdot K}^{\mathrm{L}}{ }_{1}(h),\right. \\
& \left.X_{\cdot_{K}}^{\overline{\mathrm{R}}}(h), X_{\cdot K+1}^{\mathrm{L}}(h), \ldots, X_{\cdot m}^{\mathrm{L}}(h)\right)
\end{aligned}
$$

$$
\begin{aligned}
X^{\overline{\mathrm{R}}}(h: K)= & \left(X_{\cdot{ }_{1}}^{\overline{\mathrm{R}}}(h), \ldots, X_{\cdot K}^{\overline{\mathrm{R}}}{ }_{1}(h),\right. \\
& \left.X_{\cdot_{K}}^{\overline{\mathrm{L}}}(h), X_{\cdot K+1}^{\overline{\mathrm{R}}}(h), \ldots, X_{\cdot m}^{\overline{\mathrm{R}}}(h)\right)
\end{aligned}
$$

と等義する。ただし， $X_{\cdot k}^{\mathrm{L}}(h), X_{* k}^{\bar{R}}$ は，それぞれ， $X^{\mathrm{L}}(h), X^{\mathrm{R}}(h) の$ 第 $k$ 列である。闬㥞に,

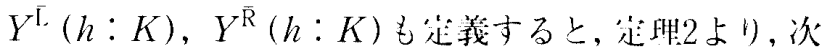
式が得られる。

$\operatorname{cl}\left((\tilde{X})_{1-h} \times(\widetilde{Y})_{1-h}\right) \subseteq E F_{K}$

$\Longleftrightarrow\left\{\begin{array}{l}\hat{\theta}_{K}\left(X^{\bar{L}}(1-h: K), Y^{\overline{\mathrm{R}}}(1-h: K)\right)=1, \\ \hat{\boldsymbol{u}}^{K}\left(X^{\bar{L}}(1-h: K), Y^{\overline{\mathrm{R}}}(1-h: K)\right)=\mathbf{0},(46) \\ \hat{\boldsymbol{v}}^{K}\left(X^{\bar{L}}(1-h: K), Y^{\overline{\mathrm{R}}}(1-h: K)\right)=\mathbf{0}\end{array}\right.$

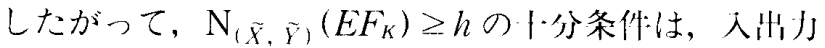
デー夕を $\left(X^{\bar{\Gamma}}(1-h: K), Y^{\overline{\mathrm{R}}}(1-h: K)\right)$ として, 閣 題(1)を解けば寒易に確認できる。

いま, 式(46)の檤が成记しないとすると, $\mathrm{N}_{(\widetilde{X}, \widetilde{Y})}$ $\left(E F_{K}\right) \geq h$ が成的すると断けできない。しかし，筐理1 より，DMU $U_{K}$ の活動 $\left(X \cdot_{K}, Y_{*_{K}}\right)$ を次式で走垡される $\left(X_{\cdot K}^{\text {new }}, Y_{\cdot K}^{\text {new }}\right)$ に收善すれば, $\mathrm{N}_{(\tilde{X}, \tilde{Y})}\left(E F_{K}\right) \geq h$ が成市。 する，すなわち，DMUKは必然性の度合 $h$ 以はで效摔 的であると断㝒できる。

$$
\begin{aligned}
\widetilde{X}_{\cdot K}^{\text {new }}=\hat{\theta} & \left(X^{\overline{\mathrm{L}}}(1-h: K), Y^{\overline{\mathrm{R}}}(1-h: K)\right) \widetilde{X}_{\cdot K} \\
& -\hat{\boldsymbol{a}}\left(X^{\overline{\mathrm{L}}}(1-h: K), Y^{\overline{\mathrm{R}}}(1-h: K)\right)
\end{aligned}
$$

$$
\widetilde{Y}_{\cdot K}^{\text {new }}=\widetilde{Y}_{\cdot K}+\hat{v}\left(X^{\mathrm{L}} \cdot(1-h: K), Y^{\mathrm{R}}(1-h: K)\right)
$$

\section{6. ニつのアプローチの関係}

$D M U_{K}$ が $\mathrm{D}$ 效摔的になる活動 $(X, Y)$ の集今 $D E F_{K}$ は，

$$
D E F_{K}=\left\{(X, Y) \geq\left(E_{x}, E_{y}\right) \mid \hat{\theta}(X, Y)=1\right\}
$$

と其ける。先䧉2より， $\hat{\theta}(X, Y)$ は捙続であるから， $D E F_{K}$ は閉集命となる。

$D M U_{K}$ が $\mathrm{D}$ 效摔的となる叮能性上必然性の度合を 考えると, $\mathrm{N}_{(\bar{X}, \tilde{Y})}\left(D E F_{K}\right)=1-\Pi_{(\widetilde{X}, \bar{Y})}\left(\left(D E F_{K}\right)^{\mathrm{c}}\right)$, お よび，盗義より川らかに，

$$
\begin{aligned}
& \Pi_{(\tilde{X}, \tilde{Y})}\left(D E F_{K}\right)=\mu_{\hat{\theta}(\tilde{X}, \bar{Y})}(1) \\
& \mathrm{N}_{(\tilde{X}, \bar{Y})}\left(D E F_{K}\right)=1-\sup _{r, 1} \mu_{\hat{\theta}(\tilde{X}, \tilde{Y})}(r)
\end{aligned}
$$

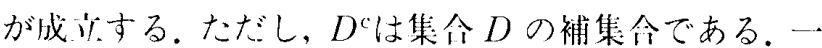
$j_{j}, E F_{K} \subseteq D E F_{k}$ より,

$$
\begin{aligned}
& \Pi_{(\tilde{X}, \tilde{Y})}\left(E F_{K}\right) \leq \Pi_{(\tilde{X}, \tilde{Y})}\left(D E F_{K}\right) \\
& \mathrm{N}_{(\tilde{X}, \tilde{Y})}\left(E F_{K}\right) \leq \mathrm{N}_{(\tilde{X}, \tilde{Y})}\left(D E F_{K}\right)
\end{aligned}
$$

となるので，次式が成市する。

$$
\begin{aligned}
& \Pi_{(\hat{X}, \tilde{Y})}\left(E F_{K}\right) \leq \mu_{\hat{\theta}(\tilde{X}, \tilde{Y})}(1) \\
& \mathrm{N}_{(\bar{X}, \tilde{Y})}\left(E F_{H}\right) \leq 1-\sup _{r, 1} \mu_{\hat{\theta}(\tilde{X}, \tilde{Y})}(r)
\end{aligned}
$$

特に，すべての型関数 $L_{i k}^{\times}$と $R_{i k}^{\times}$,あるいは，すべての 型関数 $L_{j k}^{y}$ と $R_{j k}^{y}$ が速繶な関数であるとき，式(54)， （55）が等少で成胡することが，次の分理に少えられて いる。

定理6 型蔺数 $L_{i k}^{\mathrm{x}}, R_{i k}^{\mathrm{x}}, i=1,2, \ldots, m, k=1,2, \ldots, n$ が速続な烕数であるとき，

$$
\begin{aligned}
& \mathrm{II}_{(\tilde{X}, \tilde{Y})}\left(E F_{K}\right)=\mu_{\hat{\theta}(\tilde{X}, \tilde{Y})}(1) \\
& \mathrm{N}_{(\tilde{X}, \tilde{Y})}\left(E F_{K}\right)=1-\sup _{r \in 1} \mu_{\hat{\theta}(\tilde{X}, \tilde{Y})}(r)
\end{aligned}
$$

が成立する。闬様に， $L_{j k}^{y}, R_{j k}^{y}, j=1,2, \ldots, s, k=$ $1,2, \ldots, n$ が連繥な関数であるとき，式(56)，(57)が成 けする。

（証明）似定より， $L_{i k}^{\times}$は非減少で連続であるから， $\left(L_{i k}^{\mathrm{x}}\right)^{(-1)}$ は綮密济減少関数になる。 $\left(R_{i k}^{\mathrm{x}}\right)^{(-1)},\left(L_{j k}^{\mathrm{y}}\right)^{(-1)}$

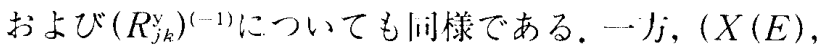
$Y(\Delta))$ を

$$
X_{\cdot_{k}}(E)=\left\{\begin{array}{l}
X_{\cdot_{k}}-E_{\cdot_{k}}, \quad \text { if } k=K, \\
X_{\cdot_{K}}+E_{\cdot_{K}}, \quad \text { if } k \neq K,
\end{array}\right.
$$




$$
Y_{{ }_{k}}(\Delta)=\left\{\begin{array}{l}
Y_{\cdot_{k}}+\Delta \cdot \cdot_{k}, \quad \text { if } k=K, \\
Y_{\cdot_{K}}-\Delta \cdot \cdot_{K}, \text { if } k \neq K .
\end{array}\right.
$$

と定義すると, $\hat{\theta}_{K}(X, Y)=1$ かつ $\sum_{i=1}^{m} \hat{u}_{i}^{K}(X, Y)+$ $\sum_{j=1}^{s} \hat{v}_{j}^{K}(X, Y)>0$ であるとき, $E>O_{m}^{n}$ かつ $\Delta \geq O_{s}^{n}$, ある いは, $E \geq O_{m}^{n}$ かっ $\Delta>O_{s}^{n}$ なる任意の $(E, \Delta)$ について， $\hat{\theta}_{K}(X(E), Y(\Delta))=1, \quad \sum_{i=1}^{m} \hat{u}_{i}^{K}(X(E), \quad Y(\Delta))+$ $\sum_{j=1}^{s} \hat{v}_{j}^{K}(X(E), Y(\Delta))=0$ が成立することが容易に示 せる。これらの性質を胢いると， $\hat{\theta}_{K}\left(X^{\mathrm{R}}(h: K)\right.$, $\left.Y^{\mathrm{L}}(h: K)\right)=1$ であるき，任意の $\varepsilon>0$ に対して， $\hat{\theta}_{K}\left(X^{\mathrm{R}}(h-\varepsilon: K), Y^{\mathrm{l}}(h-\varepsilon: K)\right)=1, \mathfrak{a}^{K}\left(X^{\mathrm{R}}(h-\varepsilon:\right.$ $\left.K), Y^{\mathrm{L}}(h-\varepsilon: K)\right)=\mathbf{0}$ かつ $\hat{\boldsymbol{v}}^{K}\left(X^{\mathrm{R}}(h-\varepsilon: K)\right.$, $\left.Y^{\mathrm{L}}(h-\varepsilon: K)\right)=0$ となる.したがって, $\Pi_{(\tilde{X}, \tilde{Y})}\left(E F_{K}\right)$ $=\Pi_{(\tilde{X}, \tilde{Y})}\left(D E F_{K}\right)$ が示され, 式(56)が成立する.式(57) についても间様に証明できる。

定理6より，ファジィ入力データか，もしくは，ファ ジィ出力デー夕がすべて連続なメンバシップ関数をも つ凸なファジィ数であれば，式(56)，(57)が成立する ことを示している。

\section{7. 数值例}

表1に示すファジィ入力データをもつ七つの活動 ( $\boldsymbol{x}$, $y$ ），提案したファジィ入出力デー夕に对するDEA により解析しよう。ただし， $\boldsymbol{x}=\left(x_{1}, x_{2}\right)$ である。表1に おいて, 型関数 $L$ は $L(r)=1-r$ と定義される。した がって, 表1のファジィ入力データはすべて三解ファ ジィ数で表される. 出力 $y$ がすべて1であることより, 入力 $x_{1}$ を横軸に, 入力 $x_{2}$ を縦軸にとった冬データのグ ラフを図1に示す。冬データはピラミッド型のファジィ ベクトルになるので, 四1ではそれを、から見たものを 示している.

DEAでは，実現しうる活動の集合を，」えられた入 出力データ $(X, Y)$ に基づき

$$
\begin{aligned}
& P=\left\{(\boldsymbol{x}, \boldsymbol{y}) \mid x_{i}\right. \geq \sum_{k=1}^{n} \lambda_{k} x_{i k}, y_{j} \leq \sum_{k=1}^{n} \lambda_{k} y_{j k}, \\
& \lambda_{k} \geq 0, \quad i=1,2, \ldots, m, \\
&j=1,2, \ldots, s, \quad k=1,2, \ldots, n\}
\end{aligned}
$$

と定義し，生産可能集含と呼んでいる。四1の折線 $l_{1}$ お よびl $l_{3}$ はそれぞれ，ファジィ人ノデー夕が方えられた

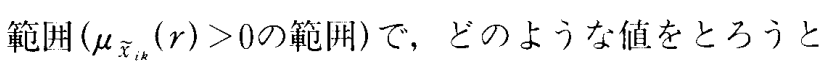
も生産可能となる集命(確实に牛産叮能となる活動の

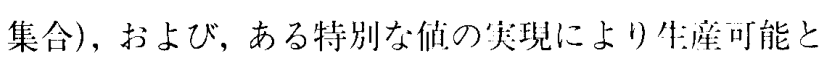
なる集命(生産叮能となりうる活動の集命)の境界を小 している。また， $l_{2}$ は冬ファジィ人カデータの中心值よ り求められる牛产叮能集命を表している。

各活動について, $\hat{\theta}_{K}(\tilde{X}, Y)$ を求めた結果を四2に示 す.网2に示すように, $D M U_{3}, D M U_{4}, D M U_{5}$ で, $\mu_{\hat{\theta}_{k}}(\tilde{X}, Y)$ (1) $=1, K=3,4,5$ となった。したがって, 定理6より, $\Pi_{(\widetilde{X}, Y)}\left(E F_{K}\right)=1, K=3,4,5$ となる. 一 $)_{j}, K=1,2,6,7$

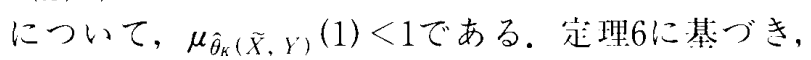
$\Pi_{(\tilde{X}, Y)}\left(E F_{K}\right), K=1,2,6,7$ を求好ると,

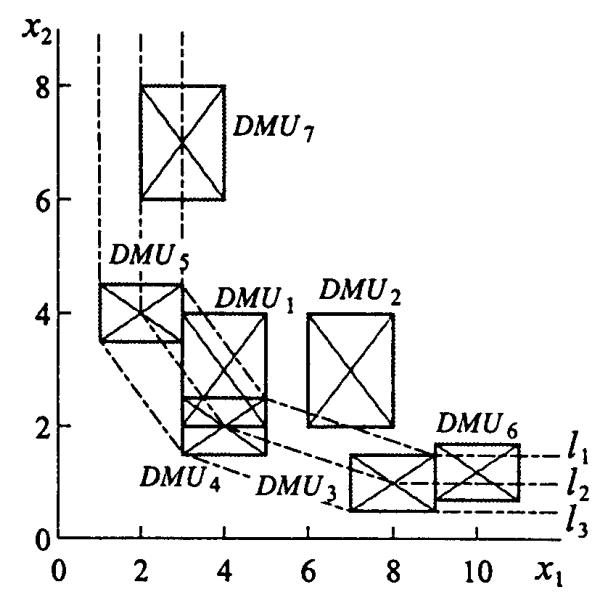

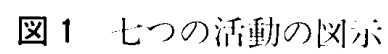

\begin{tabular}{|c|c|c|c|c|c|c|c|}
\hline & $\overline{\mathrm{DMU}}_{1}$ & $\overline{\mathrm{DMU}_{2}}$ & $\mathrm{DMU}_{3}$ & $\mathrm{DMU}_{4}$ & $\mathrm{DMU}_{5}$ & $\mathrm{DMU}_{6}$ & $\mathrm{DMU}_{7}$ \\
\hline & $\overline{(4,4,1,1)_{L L}}$ & $(7,7,1,1)_{L L}$ & $(8,8,1,1)_{L L}$ & $(4,4,1,1)_{L L}$ & $(2,2,1,1) L Z$ & $(10,10,1,1)_{L L}$ & $(3,3,1,1)_{L L}$ \\
\hline 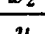 & $\frac{1}{1}$ & 1 & 1 & 1 & $(2,-8,0,0 \times 1 / 2$ & 1 & $\frac{1,1,2}{1}$ \\
\hline
\end{tabular}

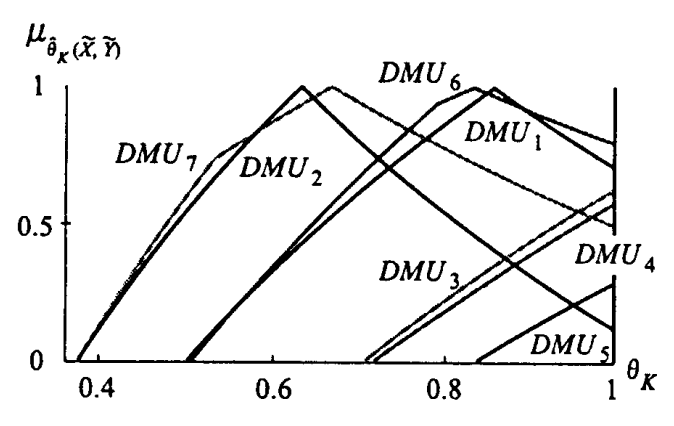

図 2 七つの活動に対するファジィ D 效摔佔

表 1 ファジィ人カデータをもつ七つの活動 


$$
\begin{aligned}
& \Pi_{(\tilde{X}, Y)}\left(E F_{1}\right)=\mu_{\hat{\theta}_{1}(\tilde{X}, Y)}(1)=0.714 \\
& \Pi_{(\tilde{X}, Y)}\left(E F_{2}\right)=\mu_{\hat{\theta}_{2}(\tilde{X}, Y)}(1)=0.125 \\
& \Pi_{(\tilde{X}, Y)}\left(E F_{6}\right)=\mu_{\hat{\theta}_{6}(\tilde{X}, Y)}(1)=0.800 \\
& \Pi_{(\tilde{X}, Y)}\left(E F_{7}\right)=\mu_{\hat{\theta}_{7}(\tilde{X}, Y)}(1)=0.500
\end{aligned}
$$

が得られる。

一方, $\mathrm{N}_{(\tilde{X}, Y)}\left(E F_{K}\right)$ の倠は, $K=1,2,6,7$ に刘して, 式 $(24)$ より， $\mathrm{N}_{(\tilde{X}, Y)}\left(E F_{K}\right)=0$ となり，K=3,4,5につ いて算出すると, 定理6より,

$$
\begin{aligned}
& \mathrm{N}_{(\tilde{X}, Y)}\left(E F_{3}\right)=1-\sup _{r<1} \mu_{\hat{\theta}_{3}(\tilde{X}, Y)}(r)=0.469 \\
& \mathrm{~N}_{(\tilde{X}, Y)}\left(E F_{4}\right)=1-\sup _{r<1} \mu_{\hat{\theta}_{4}(\tilde{X}, Y)}(r)=0.418 \\
& \mathrm{~N}_{(\tilde{X}, Y)}\left(E F_{5}\right)=1-\sup _{r<1} \mu_{\hat{\theta}_{5}(\tilde{X}, Y)}(r)=0.709
\end{aligned}
$$

が得られる。

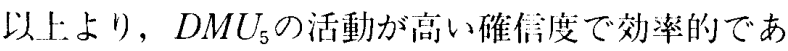
るといえ， $D M U_{3}, D M U_{4}$ の活動については，中程度の 確信度で效率的であるといえる。一力，他の活動につ いては，確信して效率的であるとはいい難く，效摔的 であるかもしれないとしかい之ない，その川能性は， $D M U_{1}, D M U_{6}$ の活動については高く，DMU について は中程度であるが, $D M U_{2}$ につては低く，はぼありえ ないともいえる。これらの分析結果は，悯1を見れば理 解できる。すなわち，折線 $l_{2}$ は， $D M U_{3}, D M U_{4}, D M U_{5}$ のファジィ人打データの吣を頂点としていることよ り， $\mathrm{N}_{(\tilde{X}, Y)}\left(E F_{K}\right)>0, K=3,4,5$ が理解できる. $D M U_{5}$

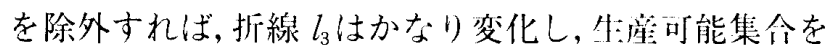
示古 $l_{3}$ りり存に:の領域がかなり小さくなる一方, $D M U_{3}, D M U_{4}$ のいずれかを除外しても，折線 $l_{3}$ は大き く変化しない。これより， $\mathrm{N}_{(\widetilde{X}, Y)}\left(E F_{5}\right)$ が大きく， $\mathrm{N}_{(\tilde{X}, Y)}\left(E F_{K}\right), K=3,4$ 古れほど大きくないことが 理解できる. $D M U_{2}$ のファジィ人力デー夕は, 折線 $l_{1}$ よ り隹にに位置していることより， $\Pi_{(\bar{X}, Y)}\left(E F_{2}\right)$ が小さ くなること,および, $D M U_{7}$ のファジィ入やデー夕が折 線 $l_{2}$ に接し,半分が折線 $l_{1}$ の有にあることより, $\Pi_{(\tilde{X}, Y)}\left(E F_{7}\right)$ $=0.5$ となることが理解できる. $\Pi_{(\bar{X}, Y)}\left(E F_{1}\right)$,

$\Pi_{(\tilde{X}, Y)}\left(E F_{6}\right)$ についても, $D M U_{1}, D M U_{6}$ のファジィ人 力デー夕と折線 $l_{1}, l_{2}$ の位置関係から理解できる.

次に, $D M U_{2}$ の活動について, 高い叮能性で效洋的で あるといえるための一つの收善案を考えよう。叮能性 の度合がほぼ0.7以トで，高い四能性といえるとしよ j. 式 $(37),(38)$ より, $\hat{\theta}_{2}\left(X^{\mathrm{R}}(0.7: 2), Y^{\mathrm{L}}(0.7:\right.$ 2)), $\hat{\boldsymbol{u}}^{2}\left(X^{\mathrm{R}}(0.7: 2), Y^{\mathrm{L}}(0.7: 2)\right), \hat{\boldsymbol{v}}^{2}\left(X^{\mathrm{R}}(0.7:\right.$ $\left.2), Y^{\mathrm{L}}(0.7: 2)\right)$ を求めればよい. $\hat{\theta}_{2}\left(X^{\mathrm{R}}(0.7: 2)\right.$, $\left.Y^{\mathrm{L}}(0.7: 2)\right)=0.737, \hat{\boldsymbol{a}}^{2}\left(X^{\mathrm{R}}(0.7: 2), Y^{\mathrm{L}}(0.7:\right.$
2) $=\mathbf{0}, \hat{\boldsymbol{v}}^{2}\left(X^{\mathrm{R}}(0.7: 2), Y^{\mathrm{L}}(0.7: 2)\right)=0$ が得られる ので, $D M U_{2}$ の活動における人少0.737倍に縮小すれ ば, $\Pi_{(X, Y)}\left(E F_{2}\right) \geq 0.7$ となり, 亶い可能性で効媇的で あるといえる。

间様に, $D M U_{5}$ の活動が, わずかな確信度ででも効率 的であるといえるための一つの改善案を考えよう。必 然性の度令が0.05以トであることが，確信度がわずか あるといえるとしよう。式 $(47),(48) よ り ， \hat{\theta}_{K}\left(X^{\bar{L}}\right.$ $\left.(0.95: 5), Y^{\overline{\mathrm{R}}}(0.95: 5)\right), \hat{\boldsymbol{a}}^{k}\left(X^{\overline{\mathrm{L}}}(0.95: 5), Y^{\overline{\mathrm{R}}}\right.$ $(0.95: 5)), \hat{v}^{k}\left(X^{\overline{\mathrm{L}}}(0.95: 5), Y^{\overline{\mathrm{R}}}(0.95: 5)\right)$ を求め ればよい。これらを求めると， $\hat{\theta}_{K}\left(X^{\overline{\mathrm{L}}}(0.95: 5), Y^{\overline{\mathrm{R}}}\right.$ $(0.95: 5))=0.796, \hat{\boldsymbol{u}}^{K}\left(X^{\overline{\mathrm{L}}}(0.95: 5), Y^{\overline{\mathrm{R}}}(0.95:\right.$ $5))=(0.049,0), \hat{\boldsymbol{v}}^{K}\left(X^{\mathrm{L}}(0.95: 5), Y^{\overline{\mathrm{R}}}(0.95: 5)\right)=$ 0となり，DMU,の活動に抢ける人打 $\left(x_{1}, x_{2}\right)$ を0.796倍 に絔小し，維小した入少小 $x_{1}$ をさらに0.049だけ小さく すれば, $\mathrm{N}_{(\tilde{X}, Y)}\left(E F_{5}\right) \geq 0.05$ となり，わずかな確信度で 刘率的になる。

\section{8. おわりに}

本研究では，ファジィ入出力データに対するDEA について考祭し，自然なつつのアプローチを提案した。 まず，DEAに打いて解かれる線形计再問題を，与えら れた人悕小データに対してD效率值を対忍させる写 像とみなし，拡張原理を適用してD效摔値のファジィ 集合を求好るj法を議論した。この写像が連続である ことや羊淍であることを示古とともに，分解原理を適 用すれば，D效倠值のファジィ集合が線形鲉曲法を繰 り这し適月することにより，近似的に算出できること を述べた。次に，DEAにおける效摔性を叮能性理論に

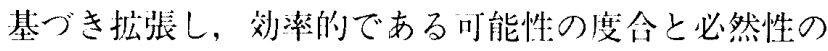
度合を起義するとともに，「之られな度合以上で叮能 的に，あるいは，必然的に效衔的であるか否かを判定 子るう法を議論した。また，方えられた度合で效率的 でない埸令に，その度命で效㻭的になるための一改善 案を求好るお法も議論した。結果として，2段階線形計 油閏題を解くことにより，与えられた度合以にで效率 的であるか否かつ判定と效倠的でない場命の一改善案 が求められることをホした。さらに、これら二つのア プローチの関係を調べ，ファジィ人出力データが凸で あり，そのメンバシップ関数が連続であれば，D效率 值のファジィ集命から效摔的である可能性の度合，必 然性の度合が求められることを明らかにした，最後に， 数做例を过之，提案法に上る解析才j法を説明した。

なお, 本研劣では, DEAにおいて，人力の收善を意 㲸した人」型モデル [1]を取り扱ったが, 出力の改善を 意汹した出力型モデル[1]についても闰様に,ファジィ 人出打データの場命入搪非寸ることができる。 
今後は, ファジィ入出力デー夕に対する他の DEA による解析法 [8]の確立やそれらの相互関係の議論を 試みるつもりである。また，通常，入力が大きければ 出力も大きくなるといった相互関係が入力デー夕と出 カデー夕に存在すると考えられる。このような相互関 係がある場合のファジィ入出力データに対する DEA についても，今後の研究課題である。

[1]刀根 薰：経営効率性の測定と改善 一包絡分析法 DEA によるー，日科技連 (1993)。

[2]上田 徹：包絡分析法DEA とファジィ DEA，日本ファ ジィ学会誌, Vol.10, No.2, 193-199(1998).

[3]上田, 上村：三角型ファジィ数を用いた DEA, 第13回フ アジィシステムシンポジウム講演論文集, 681682(1997).

[4]P. Guo and H. Tanaka: Fuzzy DEA with Fuzzy Data, 第13回ファジィシステシンポジウム講演論文集, 685-686 (1997).

[5]M. Inuiguchi, H. Ichihashi and H. Tanaka : Fuzzy Programming: A Survey of Recent Developments, in R. Slowinski and J. Teghem (Eds.), Stochastic versus Fuzzy Approaches to Multiobjective Mathematical Programming under Uncertainty, Kluwer Academic Publishers, 45-68(1990).

[6]W. W. Hogan : Point-to-Set Maps in Mathematical Programming, SIAM Review, Vol.15, No.3, 591603(1973).
[7]D. Dubois and H. Prade : Fuzzy numbers: An overview, in J. C. Bezdek (Ed.), Analysis of Fuzzy Information, Vol.I : Mathematics and Logic, CRC Press, Boca Raton, FL, 3-39, (1987).

[8]M. Inuiguchi and T. Tanino: Various Possible and Necessary Extensions of Efficiency in DEA with Interval Input-Output Data, Proceedings of Third European Workshop on Fuzzy Decision Analysis and Neural Networks for Management, Planning and Optimization, 50-59(1998).

[9]松下，高萩：入出力値をファジィ集合にした DEA，第2 回曖昧な気持ちに挑むワークショップ，93-96(1997).

注 1

D 効率值をファジィ集合により求めることに関しては, 本研究を口頭発表した約 1 ヶ月後に，独立に，松下，高萩 [9] によっても口頭発表により提案されている。ただし，文献 [9]では，専ら D 効率值のファジイ集合を求めており，効摔 性の可能性理論に基づく拡張などの議論はない。

[問い合わせ先]

（1998年8月27日＼cjkstart受付）

₹565-0871

吹田市山田丘2-1

大阪大学大学院士学研究科

電子情報エネルギー工学専攻

乾口 雅弘

TEL : 06-6879-7787

FAX : 06-6879-7939

E-mail : inuiguti@eie.eng.osaka-u.ac.jp

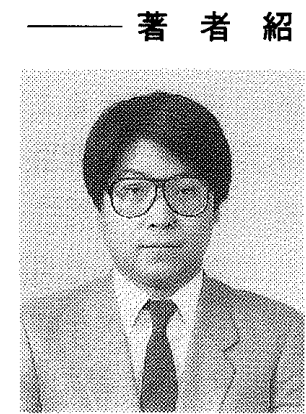

介

乾口 雅弘(いぬいぐちまさいろ)

大阪大学大学院工学研究科電子情報工ネ ルギー工学専攻

1987年 大阪府立大学大学院士学研究 科博士前期課程 (経営工学専攻) 修了。同 年 同大学経営工学科助手, ' 92 年. 広島大 学工学部第二類 (電気系) 計数管理工学講 座助教授, '97年 大阪大学大学院工学研 究科笔子情報エネルギー工学専攻助教授， 現在に至る。主として, 可能性理論, Dempster-Shafer 理論, ファジイ数理計 画法抢よび近似的推論法に関する研究に 従事. '91年 システム制御情報学会椹木 記念賞奨励賞, ’93年 月本ファジィ学会 奖励賞, '97年 日本ファジィ学会論文賞, 受賞. 博士 (工学)。計測自動制御学会, 国 際ファジィシステム学会, システム制御 情報学会, 電子情報通信学会, 日本オペレ ーションズ・リサーチ学会, 日本経営工学 会, 日本ファジィ学会などの会員.

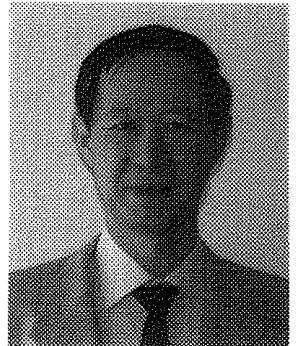

谷野 哲三(たにのてつぞう)

大阪大学大学院工学研究科電子情報エネ ルギー工学専攻

1973年3月 京都大学厂学部数理工学科 卒業. 1978年3月同大学大学院 L学研究 科数理工学専攻博士課程修了. 東北大学: 工学部助教授，岡山大学工学部教授を経 $\tau$, 現在大阪大学大学院工学研究科電子 情報エネルギー工学専攻教授。最適化理 論, 意思決定論, ゲーム理論などの研究に 従事. 工学博士. 計測自動制御学会, シス テム制御情報学会, 日本 OR 学会, 日本応 用数理学会，電子情報通信学会などの会 員. 


\section{Possibilistic DEA with Fuzzy Input-Output Data}

by

\section{Masahiro INUIGUCHI and Tetsuzo TANINO}

\section{Abstract:}

In this paper, we develop a DEA (Data Envelopment Analysis) with fuzzy input-output data. There are several approaches to extend the DEA into the case of fuzzy input-output data. We made two natural extension approaches. In the first approach, a linear programming problem solved in the conventional DEA is regarded as a mapping from an input-output data set to a D-efficiency value set. Applying the extension principle to the mapping, we obtain a fuzzy set of D-efficiency values from given fuzzy input-output data. In the second approach, we propose an efficiency analysis based on possibility theory. By this approach, possible and necessary efficiencies are defined. We discuss improvement guides for a DMU (Decision Making Unit) to be possibly and necessarily efficient to a given degree. The relations between the fuzzy set of D-efficiency values and the possibilistic efficiency analysis are investigated. A numerical example is given to illustrate the proposed analyses.

Keywords : DEA, Fuzzy Input-Output Data, Extension Principle, Possibility Theory, Linear Programming, Efficiency

\section{Contact Address : Masahiro INUIGUCHI}

(iraduate School of Engineering, Osaka University

2-1, Yamadaoka. Suita, Osaka 565-0871, Japan

TEL : $06-6879-7787$

FAX : $06-6879-7939$

E-mail : inuiguti@ eie.eng.osaka-u.ac.jp 